\title{
Optimization of human interferon beta protein expression in Chinese hamster ovary cells
}

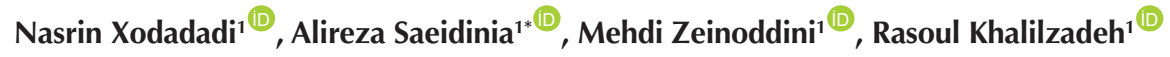 \\ ${ }^{1}$ Faculty of Chemistry and Chemical Engineering, Malek Ashtar University of Technology, Tehran, Iran
}

*Corresponding Author: Alireza Saeidinia, Faculty of Chemistry and Chemical Engineering, Malek Ashtar University of Technology, Tehran, Iran. Postcode: 1774-15875. Telephone: +982122945141, Fax: +982122935341, Email: ar_saeedi@ mut.ac.ir

\begin{abstract}
Background and aims: Human interferon beta-1a (hIFN $\beta-1 \mathrm{a}$ ) is a $22.5-\mathrm{kDa}$ glycoprotein used to treat diseases such as multiple sclerosis (MS). Because of appropriate post-translation modifications, protein isolation, and lack of toxicity in Chinese hamster ovary (CHO) cells, we cloned hIFN $\beta-1$ a encoding sequence into these cells by recombinant DNA technology to achieve stable expression of this recombinant protein.

Methods: The hIFN $\beta-1$ a encoding sequence was designed based on the $\mathrm{CHO}$ cells' codon usage and the Gene Bank data, and then syntactically constructed in the pUC57 vector. After confirmation, the synthesized sequence was cloned into the pcDNA3.1 expression vector by using EcoRI and Xhol sites via Escherichia coli DH5 $\alpha$ competent cells. Then, the recombinant vector pcDNA-hHIFN $\beta 1$ a was linearized by $\mathrm{BgIII}$ and transfected into the $\mathrm{CHO}$ cells using lipofectamine. The transfected cells were proliferated and screened by gentamicin. Certain concentrations of zinc sulfate, DMSO, and glycerol were used to enhance protein expression. Finally, the recombinant protein expression was qualitatively evaluated using different techniques.

Results: The hIFN $\beta 1$ a integrity was confirmed by DNA sequencing and specific software. The construction and sub-cloning of hIFN $\beta 1 a-$ pcDNA3.1 in E. coli were confirmed by colony-PCR with specific primers and restriction enzyme mapping. The screening of transfected $\mathrm{CHO}$ cells was performed using gentamicin. The protein expression was confirmed by RT-PCR, MTT assay, SDS-PAGE, and Western blot. Comparison of the optimized and control samples demonstrated that chemical treatment enhanced the protein expression.

Conclusion: We achieved the stable clones of $\mathrm{CHO}$ cells expressing the active form of human interferon beta.

Keywords: hIFN $\beta-1 \mathrm{a}, \mathrm{CHO}$ cells, pcDNA3.1 expression vector, lipofectamine, MTT assay
\end{abstract}

Received: 16 September 2019, Accepted: 20 September 2020, ePublished: 30 June 2021

\section{Introduction}

Interferons are pleiotropic cytokines with antiviral and immunomodulatory properties that are produced by host cells in response to the invasion of free pathogens, and stimulate the immune system and increase body resistance against pathogens (1). In 1992, Day et al isolated the interferon-beta gene from mouse DNA and amplified it in Escherichia coli (2). Today, recombinant beta interferon is produced in two hosts: mammalian and bacterial, known as interferon beta $1 \mathrm{a}$ (IFN $\beta-1 \mathrm{a})$ and $1 \mathrm{~b}$ (IFN $\beta-1 \mathrm{~b})$, respectively (3). The hIFN $\beta$-1a is composed of 166 amino acids and has a molecular weight of around $22500 \mathrm{Da}$.

This product is produced by recombinant DNA technology by inserting the gene responsible for interferonbeta production into the Chinese hamster ovary $(\mathrm{CHO})$ cells (4). Both natural and recombinant interferon beta are glycosylated and bind to the N-terminal of a carbohydrate complex.

Interferon-beta may limit central nervous system (CNS) damage caused by multiple sclerosis (MS) through an unknown mechanism (5). Due to the ability of mammalian cells to produce high-quality proteins with biochemical properties similar to the naturally synthesized protein, a large number of therapeutic recombinant proteins are produced by these cells today.

The hIFN $\beta$-1a can be produced in the expression hosts such as yeasts, filamentous fungi, insect cells, and plant cells, but due to different glycosylation patterns, their uses are also associated with some limitations (6). Therefore, nearly $70 \%$ of recombinant therapeutic proteins are produced by $\mathrm{CHO}$ cells. $\mathrm{CHO}$ cells have properties that make them suitable for the production of recombinant human proteins for clinical use. These cells easily undergo genetic modifications to facilitate foreign DNA entry and expression of large amounts of foreign protein, are capable of producing glycosylated proteins, and performing post-translational modifications required for protein bioactivity; product safety is another key factor that should be considered in selecting a cell host. The host cell should not contain any pathogenic factors, which may eventually be transmitted to the human body. $\mathrm{CHO}$ cells have been proven to be safe hosts for drug production. However, the specific efficiency of these cells is lower than prokaryotic hosts. For example, in the production process, they

(C) 2021 The Author(s); Published by Shahrekord University of Medical Sciences. This is an open-access article distributed under the terms of the Creative Commons Attribution License (http://creativecommons.org/licenses/by/4.0), which permits unrestricted use, distribution, and reproduction in any medium, provided the original work is properly cited. 
have been found to be unstable that is a major problem in the biotechnology industry. Also, protein instability is a common problem in the production, purification, and storage of recombinant pharmaceutical products. Besides, molecular aggregation is a major problem in the production of interferon-beta protein due to the hydrophobic nature of its structure.

There are several reports showing the tendency of nonglycosylated IFN $\beta$ to aggregate, which prevents its proper crystallization by X-ray diffraction studies. But there is a similar phenomenon in glycosylated IFN $\beta$ produced in $\mathrm{CHO}$ cells due to increased protein concentration and temperature (7).

There are several strategies for controlling and maintaining stable production of a high amount of protein, including modifications and induction of different mutations in the hIFN $\beta$-1a encoding sequence to increase the binding of RNA polymerase enzymes, but the addition of culture supplements and regulation of culture variables is also used as a simpler method with good efficiency. Improving culture conditions is critical to sustaining biological activity and increasing crop production. Increased protein expression can substantially reduce the cost and time needed to produce recombinant proteins.

Various physical (e.g. temperature (8 (and pH (9)) and chemical methods (e.g. $\mathrm{NaCl}(10)$, acetate (11), etc) have been examined to optimize the expression of hIFN $\beta$. Here, we chose three chemicals including dimethyl sulfoxide (DMSO), glycerol, and zinc.

DMSO is used as an additive in cell culture systems that reduces aggregation and cell death and also increases protein production. It stabilizes proteins in their natural conformation and acts as a chemical chaperone. Fiore and Degrassi reported that DMSO inhibits the growth of $\mathrm{CHO}$ cells and prevents their apoptosis and phenotypic differentiation. The polar nature of this substance allows it to permeate into the cell membrane without causing significant damage, but its effect on cell function has not been fully elucidated yet (12).

Glycerol is widely used as a protein stabilizer in the pharmaceutical and biotechnology industries. As an osmolyte, it can form hydrogen bonds and also a hydration shell of water molecules surrounding the protein surface. Like DMSO, this compound has also been identified as a molecular chaperone and a mediator of protein folding within cells, and also targets and detects poorly folded proteins for refolding or degradation. Glycerol has been shown to increase IFN $\beta$ stability by reducing more than $50 \%$ aggregation. It can also prevent IFN $\beta$ aggregation after isolation from the cell culture medium (7).

Zinc inhibits cell apoptosis under certain conditions, and also by altering the secondary structure of mRNA, increases its stability or binding the mRNA-stabilizing proteins. Moreover, zinc directly or indirectly inhibits one or more ribonucleases responsible for the destruction of unstable mRNAs (13).

In this study, the interferon-beta gene was cloned into
$\mathrm{CHO}$ cells, and the cells were treated with zinc sulfate, DMSO, and glycerol to increase protein expression. Finally, expression levels in untreated and chemically treated conditions were evaluated by different techniques.

Materials and Methods

Materials, vectors, and strains

Escherichia coli coli strain DH5a (Novagen, Iran), pcDNA3.1 vector (Novagen, Iran); CHO cell line (Iranian Biological Resource Center, Iran); HDF cell line (Pasteur Institute), DMEM medium (Bioidea, Iran), FBS (Bioidea, Iran); penicillin-streptomycin antibiotic solution (Gibco, USA), gentamicin antibiotic (Gibco, USA); ampicillin (Roche; Germany), trypsin-EDTA (Bioidea, Iran); Taq Polymerase DNA (Fermentase, Lithuania), T4 DNA Ligase (Fermentase, Lithuania), EcoRI, XhoI and BglII restriction enzymes (Roche; Germany), agarose, glycerol (SiGMA, USA), PBS Tablet, DMSO (Gibco, USA) Lipofectamine-2000 (Invitrogen; Carlsbad, CA), RNXPlus (Sinaclon, Iran), PVDF membrane (Roche; Germany) and other chemicals (Merck Co., Germany).

Designing and synthesis of hIFN $\beta-1$ a coding sequences HIFN $\beta$-1a coding sequence was designed based on the optimal $\mathrm{CHO}$ cell codon usage and gene bank data for hIFN $\beta$-1a gene sequencing (AAC41702), and pcDNA3.1 expression vector sequence was designed using GeneRunner version 6.1.23 Beta and SnapGene 3.2.1 software and synthesized in the EcoRV sequence within the pUC57 vector and the sequencing was conducted by Pioneer Company (France).

\section{Production and replication of recombinant expression vector}

First, the plasmid pUC57-IFN $\beta 1 \mathrm{a}$ and the shuttle vector pcDNA3.1 were amplified after transfection into competent E. coli DH5a cells and cultured on the agar plate containing antibiotic ampicillin $(100 \mathrm{mg} / \mathrm{mL})$ and incubated at $37^{\circ} \mathrm{C}$.

Since the above-mentioned vectors contain ampicillinresistant genes, recombinant cells were grown to acquire resistance, and then they were screened. The obtained colonies were selected and amplified in the broth medium containing ampicillin and incubated in a shaking incubator at $37^{\circ} \mathrm{C}$ for 18 hours. After that, the plasmid was extracted using the kit (GeneAll, Korea). The hIFN $\beta$-1a fragment was enzymatically digested and separated from pUC57 using EcoRI and XhoI restriction enzymes. The pcDNA3.1 vector was separately extracted from DH5a by DNA purification kit (GeneAll, Korea).

The ligation of hIFN $\beta$-1a fragment into the pcDNA3.1 vector was performed by the T4 DNA ligase enzyme and the product was transferred into competent E. coli $\mathrm{DH} 5 a$ cells. To screen for target colonies, PCR-PCR was performed using the forward primer 5'-GGTGGTCATATGTCTTACAATCTGCTGGGTTTCCTG-3 and the reverse primer 5'-GGTGGTTGCTCTTCCGCAGTTACG- 
GAG.

Following the cultivation of appropriate colonies and extraction of plasmid DNA from them, the production of the recombinant pcDNA-hIFN $\beta 1$ a vector was confirmed by digestion with the EcoRI and XhoI enzymes.

Finally, the recombinant vector was linearized by BglII and after gel purification by kit, the recombinant vector was prepared for transferring into $\mathrm{CHO}$ cells. All PCR products and enzymatic digestion were confirmed by $1 \%$ agarose gel electrophoresis.

\section{Cloning of the recombinant pcDNA-hIFN $\beta 1$ a vector into CHO cells}

\section{Culture of $\mathrm{CHO}$ cells}

The CHO cell line was purchased from the Genetic Resource Center in a culture flask. The appropriate medium for the growth of these cells is DMEM containing $10 \%$ FBS serum plus $1 \%$ penicillin-streptomycin antibiotic solution to prevent infection. The cell culture medium was changed every two days until the cells covered about $80 \%-90 \%$ of the flask surface. At this stage, the cells were passaged by trypsin-EDTA treatment for transferring into the plate and banking. At all stages, cells were counted with Trypan blue staining.

\section{Determination of bactericidal concentration of gentamicin (G418) for screening}

Since the pcDNA3.1 plasmid contains a G418 resistance gene, transfected cells, i.e. the cells containing the recombinant vector pcDNA-hIFN $\beta 1$ a can be isolated by the treatment of G418. For this purpose, the appropriate antibiotic concentration for $\mathrm{CHO}$ cells was first determined.

To do this, $5 \times 10^{4} \mathrm{CHO}$ cells/well were cultured in a 24-well plate and treated with different concentrations of antibiotics; the minimum concentration, which killed all cells after two weeks, was selected as the optimal concentration.

\section{Transfection of linear recombinant vector into $\mathrm{CHO}$ cells}

For transfection, $1.2 \times 10^{6} \mathrm{CHO}$ cells/well were cultured in a 6 -well plate containing $500 \mu \mathrm{L}$ DMEM, 10\% FBS, and $1 \%$ penicillin-streptomycin solution and incubated at $37^{\circ} \mathrm{C}$, 95\%-100\% humidity, and 5\% $\mathrm{CO}_{2}$. After the cells reached $80 \%$ confluency, their medium was replaced with the serum- and antibiotic-free medium for transfection after 2-4 hours. Next, $2 \mu \mathrm{g} /$ well of pcDNA-hIFN $\beta 1$ a and $2 \mu \mathrm{L}$ of lipofectamine-2000 were separately added into $150 \mu \mathrm{L}$ of DMEM in the microtubes. Five minutes later, the contents of the two microtubes were combined and incubated at room temperature for 20 minutes. Then the solution containing pcDNA-hIFN $\beta 1 \mathrm{a}$ and lipofectamine-2000 was added into the wells.

Two wells containing untransfected $\mathrm{CHO}$ cells were considered as negative controls. Plates containing cells were incubated for $6 \mathrm{~h}$ with the mentioned conditions, and then the culture medium was collected, and fresh medium containing 5\% FBS and $1 \%$ penicillin-streptomycin solution was added into the wells.

\section{Confirmation of the entry of the hIFN $\beta$-1 a coding sequence} into the CHO genome

To confirm the entry of the hIFN $\beta$-1a coding sequence into the $\mathrm{CHO}$ genome, screening was performed by the G418 antibody at the determined concentration. Since the transfected cells were resistant to gentamicin antibiotic, transfected $\mathrm{CHO}$ cell colonies survived and proliferated after two weeks of the addition of this antibiotic into the culture medium.

Increased expression of hIFN $\beta$-1a protein by chemical additives

In this study, the combination of zinc sulfate, glycerol, and DMSO was used to enhance protein expression. $\mathrm{CHO}$ cells were treated with $125 \mu \mathrm{M}$ zinc sulfate, $2 \%$ glycerol, and $1 \%$ DMSO for 6 days following transfection with pcDNA3.1-hIFN $\beta 1$. The cell media were daily collected and replaced with fresh medium containing FBS and penicillin/streptomycin, as well as the above-mentioned compounds.

\section{Assessment of interferon Beta mRNA production using} RT-PCR

At this stage, the total RNA of $10^{6}$ transfected $\mathrm{CHO}$ cells was extracted by the RNX-Plus solution and confirmed by agarose electrophoresis, showing s18 and s 28 bands on the gel. Then, cDNA was synthesized by the cDNA synthesis kit (TaKaRa). After that, standard PCR was performed using specific interferon-beta primers and analyzed by agarose electrophoresis.

\section{Assessment of protein expression using SDS-PAGE and western blotting}

To evaluate the expression of hIFN $\beta$-1a protein, culture medium containing the secreted recombinant protein and culture medium containing negative control cell after concentration by $\mathrm{PMSF}$ at $45^{\circ} \mathrm{C}, 30 \mu \mathrm{L}$ of each sample was dissolved in $20 \mu \mathrm{L}$ of sample buffer $(10 \mathrm{~mL}$ high gel buffer, $5 \mathrm{~mL}$ glycerol 100\%, 1 g SDS powder, $500 \mu \mathrm{L}$ bromophenol blue, and $1 \mathrm{~mL} 2$-mercaptoethanol to a final volume of $20 \mathrm{~mL}$ ) and poured into SDS-PAGE wells and electrophoresed at $80 \mathrm{~V}$.

In the end, the gel was immersed in a Coomassie blue solution (1 $\mathrm{g}$ of Coomassie powder, $100 \mathrm{~mL}$ of acetic acid, and $500 \mathrm{~mL}$ of methanol to a final volume of $1 \mathrm{~L}$ ) and after being placed in a decoloring solution $(100 \mathrm{~mL}$ of acetic acid and $300 \mathrm{~mL}$ of methanol to a final volume of $1 \mathrm{~L}$ ), the protein bands were evaluated.

Western blotting was performed in three steps. First, isolation of all proteins in a sample medium by size was performed using SDS-PAGE gel electrophoresis. Then, the proteins isolated on the gel were transferred to the PVDF membrane (Roche) by wet method. Finally, specific identification of the target protein was performed using 
human interferon beta-specific monoclonal antibody (Roche) until the band emerged on the membrane.

Activity evaluation of hIFN $\beta$-1 a protein by MTT assay The anti-proliferative property of interferon beta was used for this test. To this end, $8 \times 10^{3}$ human dermal fibroblasts (HDF) cell/well were cultured in a 96-well plate containing $10 \%$ DMEM and $10 \%$ FBS and incubated at $37^{\circ} \mathrm{C}$ with 95\%-100\% humidity and $5 \% \mathrm{CO}_{2}$.

After about $80 \%$ confluency, the medium samples containing interferon-beta secreted by $\mathrm{CHO}$ cells were added in pairs into the wells in volumes of $0-50 \mu \mathrm{L}$ and incubated. After 24 hours, $20 \mu \mathrm{L}$ of MTT solution $(5 \mathrm{mg}$ MTT powder in $1 \mathrm{~mL}$ PBS) was added into each well and incubated in the dark for $3 \mathrm{~h}$. Then, the wells became completely free of supernatant and $100 \mu \mathrm{L}$ of DMSO was added into each well and optical absorbance was read by ELISA reader at $570 \mathrm{~nm}$ wavelength.
Results

\section{Designing $h I F N \beta$ - 1 a coding sequence}

The hIFN $\beta$-1a coding sequence was designed based on the optimal codons of $\mathrm{CHO}$ cells and the gene bank data. The signal peptide and Kozak sequences were added to the begining of the sequence. This sequence enhances gene expression in eukaryotic systems by facilitating the binding of ribosomes to mRNA.

At the end of the gene sequence, two stop codon sequences were added so that translation completion and protein synthesis would be accomplished appropriately. EcoRI and XhoI enzymes were also selected after enzymatic mapping of the gene and vector by the SnapGene software and added to 3' and 5' sequences, respectively (Figure 1). Subsequently, the sequence of the hIFN $\beta$-1a coding sequence was inserted into the pcDNA3.1 vector by bioinformatics software (Figure 2).

Xhol cut site Kozak sequence

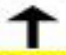

$\uparrow \uparrow$

CTCGAGACCATGACCAACAAGTGTCTCTTGCAGATTGCTCTGCTGCTGTGCTTCTCCACCACAGCTCTGTCCATGAG

CTAAACCTACTCGGATTCCTGCAGCGCTCCTCTAATTTCCAGTGCCAGAAGCTCCTGTGGCAGCTGAATGGCCGGC

TGGAGTACTGCCTCAAGGACCGGATGAACTTTGACATCCCCGAGGAGATCAAGCAGCTGCAGCAGTTCCAGAAAG

AGGACGCCGCATTGACCATCTACGAAATGCTCCAGAACATCTTTGCTATCTTTCGCCAGGATTCATCTTCCACTGGA

TGGAACGAGACTATTGTGGAGAACCTGCTGGCAAATGTGTATCACCAGATAAATCATCTGAAAACAGTTCTGGAG

GAGAAGCTGGAGAAGGAGGATTTCACCAGGGGCAAGCTCATGAGCTCCCTGCACCTGAAACGATACTATGGGCG

TATTCTGCATTACCTGAAGGCCAAAGAGTACAGTCACTGTGCCTGGACCATCGTCAGGGTGGAAATCCTGCGGAA

TIITATITCATCAATAGACTGACAGGTTACCTGAGAAACIGATGAGAATTC

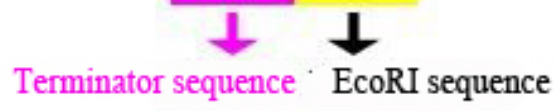

Figure 1. Encoding Sequence of the hIFN $\beta$-1a designed along with the Kozak sequence, stop sequence, cut sites, and secreted signal peptide sequence.

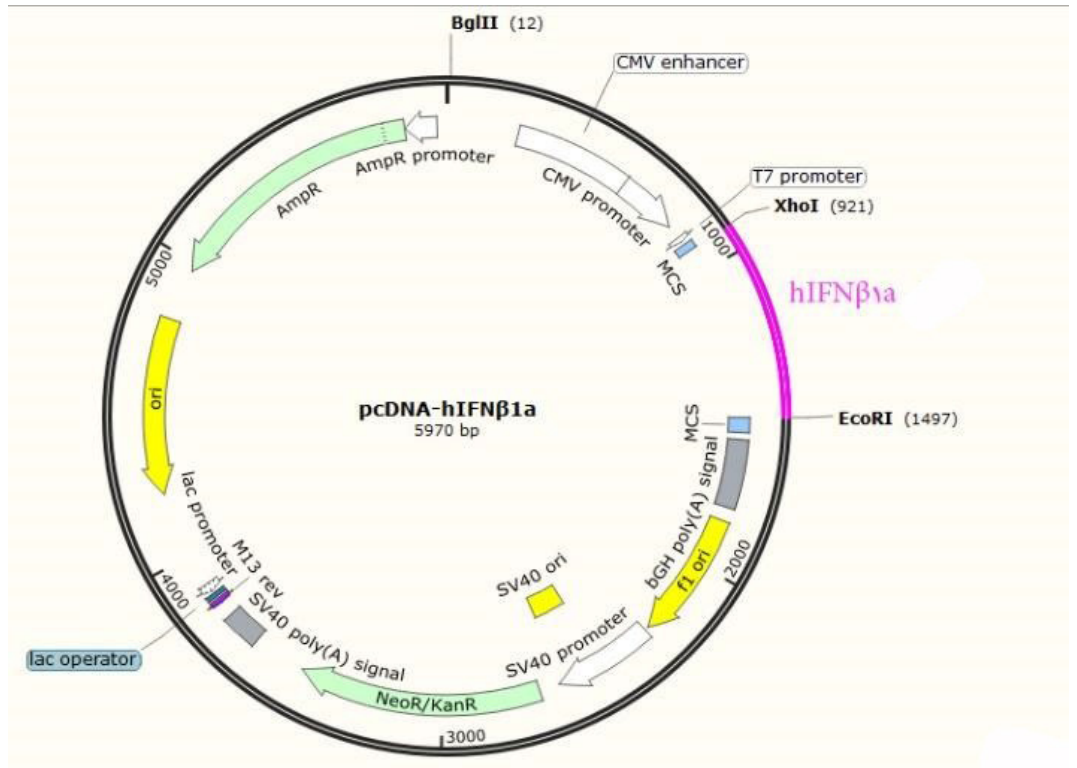

Figure 2. Bioinformatical analysis of hIFN $\beta$-1a encoding sequence entry into pcDNA3.1 plasmid by SnapGene software. 
Producing a recombinant expression vector ( $p c D N A$ hIFNB1a)

First, pUC57-IFN $\beta 1$ a plasmid was amplified by transfection into E. coli competent cells and after extraction, the above plasmid was enzymatically digested by EcoRI and XhoI enzymes to isolate the hIFN $\beta$-1a coding fragment. After cleavage of the vector with the above enzymes, two separate fragments of 2716 bp (vector) and $576 \mathrm{bp}$ (coding sequence) were expected to be formed.

As shown in Figure 3, the expected fragments appeared as bands (lines 4-9). The 5394-bp pcDNA3.1 plasmid (lanes 1 and 2) is visible on gel electrophoresis.

After purification, the hIFN $\beta$-1a coding sequence fragment was ligated inside the pcDNA3.1 by T4 ligase from the EcoRI and XhoI enzymes cut sites and transferred to $E$. coli for amplification.

A number of colonies were selected for screening the target colonies and PCR was performed using specific primers, which lead to the appearance of 576-bp fragments on gel electrophoresis (Figure 4).

Transfection of $\mathrm{CHO}$ cells with recombinant pcDNAhIFN $\beta 1$ a vector and evaluation of expression and function of recombinant $h I F N \beta$-1a protein

The recombinant vector was linearized by BglII enzyme and transferred into $\mathrm{CHO}$ cells after purification. The screening was performed using $400 \mathrm{ng} / \mathrm{mL}$ of antibiotic G418. Untransfected cells were expected to die, and recombinant vector recipient cells were expected to survive and colonize as a result of antibiotic resistance.

Figure 5 shows pre- and post-transfection and finally the formation of cell colonies after the screening, which indicates that the recombinant vector was proliferated by CHO cells.

The cDNA was synthesized from extracted RNAs and RT-PCR was performed using specific primers for the hIFN $\beta 1$ a sequence, and the product was transferred onto an agarose gel.

The observed bands confirmed the expression of the hIFN $\beta 1$ a gene at the mRNA level (Figure 6). In addition, given the sharper band in line 2 (the product under chemical treatment conditions), compared to lines 1 and 3 (untreated), the amount of hIFN $\beta$-1a mRNA production significantly increased in the chemically treated cells compared to the untreated control cells.

Subsequently, the expression of the protein secreted into the cell culture supernatant was evaluated and determined using the tests below:

SDS-PAGE: After pouring the samples into $12.5 \%$ polyacrylamide gel wells and performing electrophoresis, the appearance of the $22.5-\mathrm{kD}$ band (lanes 1 and 3) confirmed the production of beta interferon protein; the sharper lane, i.e. lane 3 is related to the sample of transfected $\mathrm{CHO}$ cells treated with zinc sulfate, glycerol,

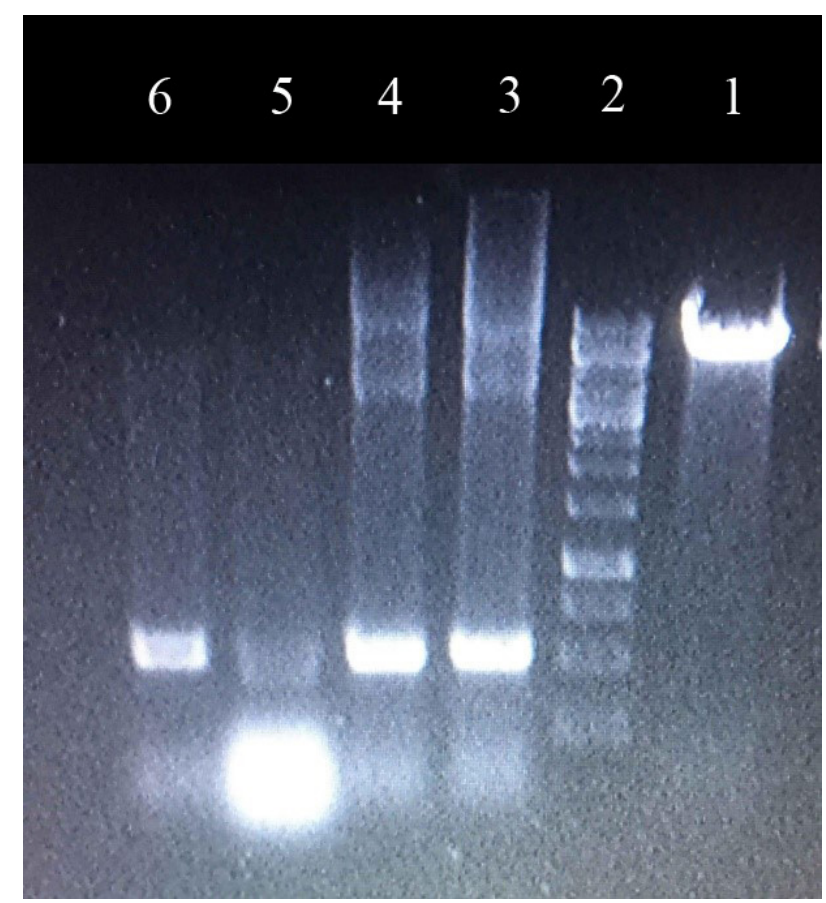

Figure 4. PCR product of the samples extracted from recombinant plasmid pcDNA-hIFN $\beta 1$ a on agarose gel 1\%. Line 1: plasmid pcDNA-hIFN $\beta 1 \mathrm{a}$. Line 2: $1 \mathrm{~kb}$ DNA ladder line. Lines 3 \& 4: Interferon-beta gene bands in the bp576 region.

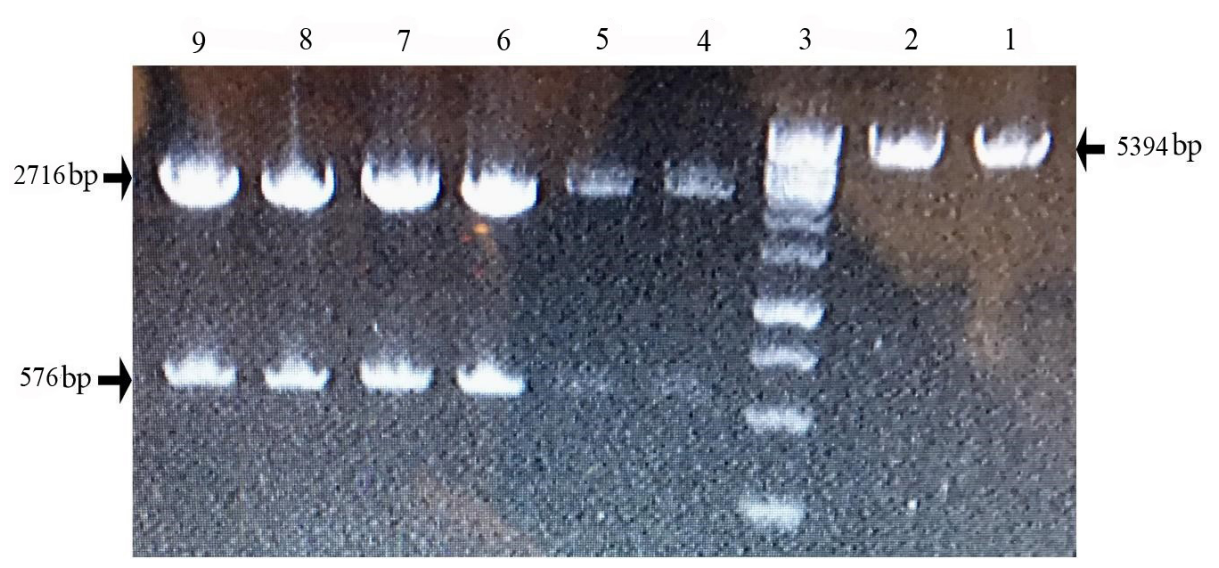

Figure 3. Enzymatic digestion product of pUC57-IFN 31 a and pcDNA3.1 plasmids by ECORI and Xhol enzymes. Lines 1 and 2: pcDNA3.1 vector. 3: $1 \mathrm{~kb}$ DNA ladder. Lines 4-9: plasmid extracts containing bp2716-pUC57 vector body bands and 576 bp-IFN $\beta 1$ a bands. 
C
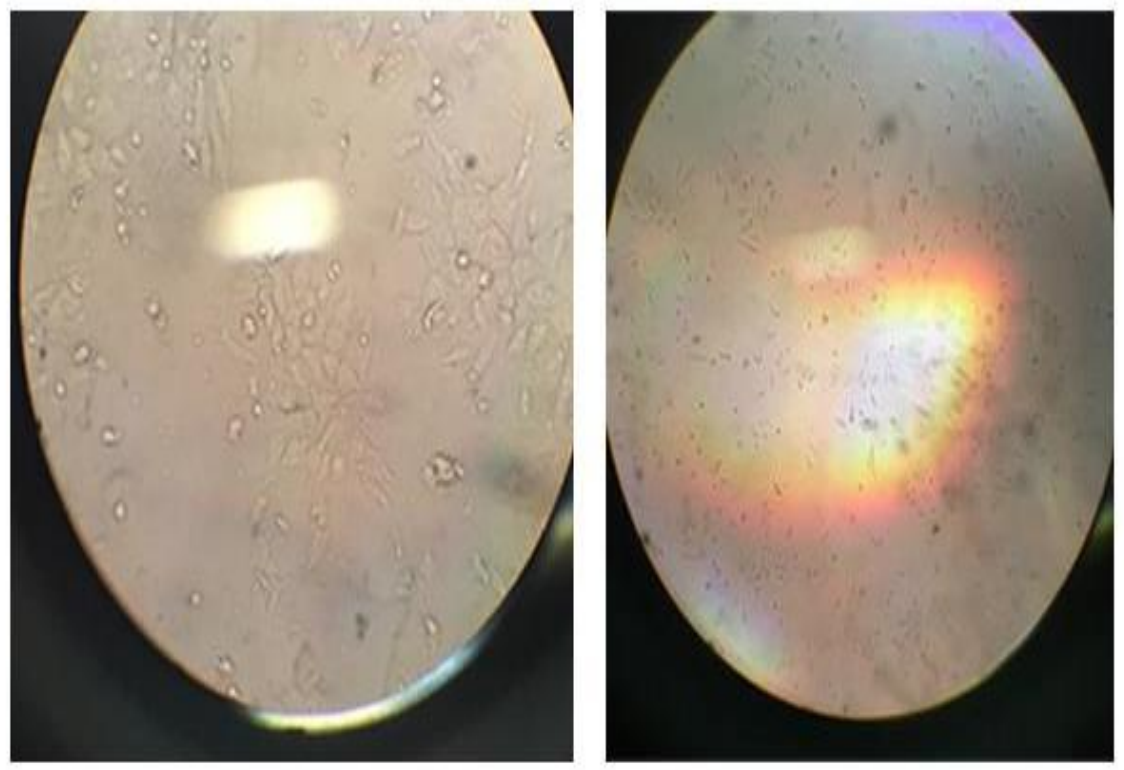

A

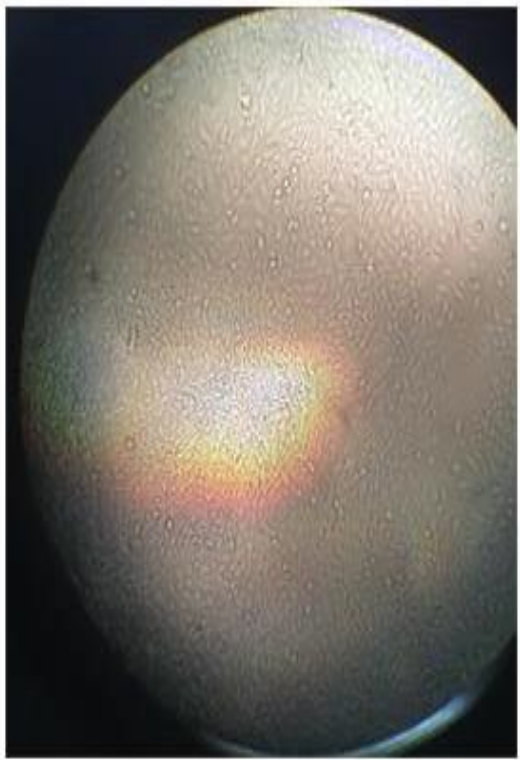

Figure 5. (A): Proliferated $\mathrm{CHO}$ cells before transfection. (B) $\mathrm{CHO}$ cells 24 hours after transfection. (C) Formation of colonies containing transfected $\mathrm{CHO}$ cells.

and DMSO, indicating increased expression compared to the untreated conditions. It should be noted that other bands formed are related to serum proteins. (Figure 7).

\section{Western blotting}

At this stage, the samples were symmetrically run on SDSPAGE and after electrophoresis, the gel was divided into two portions: one portion was stained with Coomassie blue staining solution and then decolored; the second portion was transferred onto the PVDF membrane, and after blocking by $1 \%$ BSA solution, it was treated with first

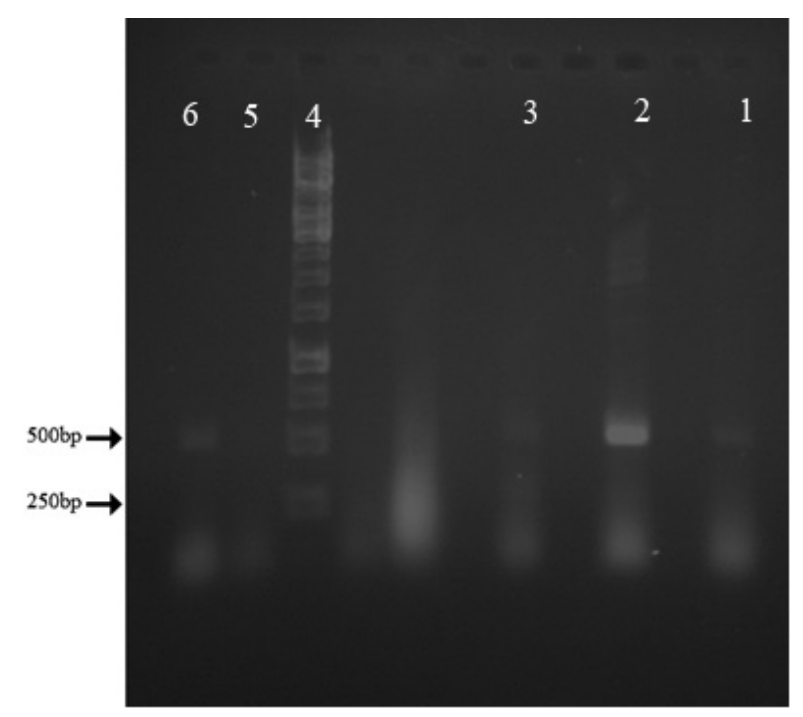

Figure 6. RT-PCR product on agarose gel $1 \%$ electrophoresis. Lines 1 and 3: RT-PCR product of untreated transfected samples. Line 2: Samples of transfected cells treated with $125 \mu \mathrm{M}$ zinc sulfate, $2 \%$ glycerol, and 1\% DMSO, line 4: $1 \mathrm{~kb}$ DNA ladder. Line 5: Negative Control. Line 6: Positive Control.

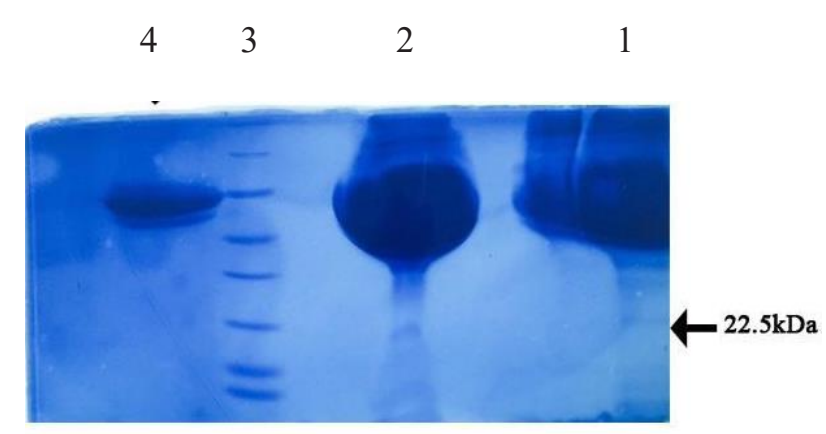

Figure 7. $12.5 \%$ Polyacrylamide gel electrophoresis containing the supernatant of transfected cells with and without chemical treatments. Line 1: Supernatant of hIFN $\beta 1$ a-producing $\mathrm{CHO}$ cells without chemical treatment. Line 2: Supernatant of $\mathrm{CHO}$ cells producing hIFN $\beta 1$ a under chemical treatments. Line 3: Unstained protein ladder. Line 4: Negative control

1:1000 antibody (antimouse) and then with the second 1:10000 antibody (specific interferon-beta antibody).

Finally, with the addition of $0.1 \mathrm{~g} / \mathrm{L} \mathrm{DAB}$, the desired band appeared and the protein expression was confirmed. In Figure 8, the emergence of the band in the $22.5 \mathrm{kDa}$ region results from the binding of the monoclonal antibody to the interferon beta protein and confirms the production of this protein.

Line 2 represents the sample obtained from transfected $\mathrm{CHO}$ cells under chemical treatment, which shows a higher expression level compared to line 1 , which is related to untreated transfected cells. Moreover, due to the concentration of the protein-containing solution, the serum proteins were also concentrated and the bubbleshape band on top of the gel is related to the serum proteins.

MTT colorimetry: The result of this test was checked by 
ELISA reader.

It was expected that with increasing concentration of hIFN $\beta 1$ a protein added to each well, due to the decreased number of living cells and consequently decreased mitochondrial succinate dehydrogenase enzyme activity, the amount of purple color produced would decrease, resulting in a decrease in the optical absorption of purple color at a wavelength of 490-540 nm. Thus, the diagram obtained with the downward trend in Figure 9 confirmed the production of this protein.

\section{Discussion}

Human interferon beta protein is a glycoprotein produced by leukocytes, lymphocytes, fibroblasts, and other immune cells. Nowadays, corticosteroids are also used to treat MS, yet with many side effects. Besides, some cancers, such as pancreatic cancer, and other diseases such as infections of the central nervous system (Clippers), liver (hepatitis C), muscles (myositis), and viral diseases (coronavirus) do not respond well to the available treatments or are associated with side effects. These can be controlled or even treated with a certain concentration of interferon betal.

The bacterial system is unable to induce glycosylation

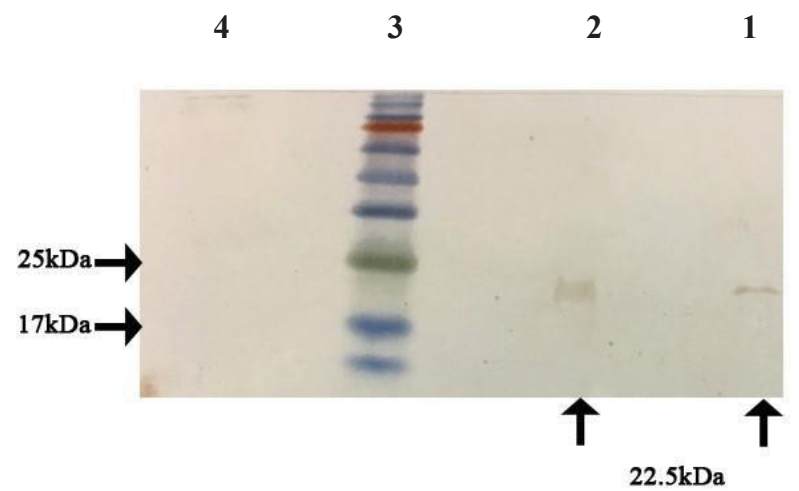

Figure 8. Western blotting analysis of hIFN $\beta$-1a protein expression. Line 1: Sample containing supernatant of cells transfected without chemicals. Line 2: Sample containing the supernatant of transfected cells treated with chemicals. Line 3: Prestained protein ladder. Line 4: Negative Control.

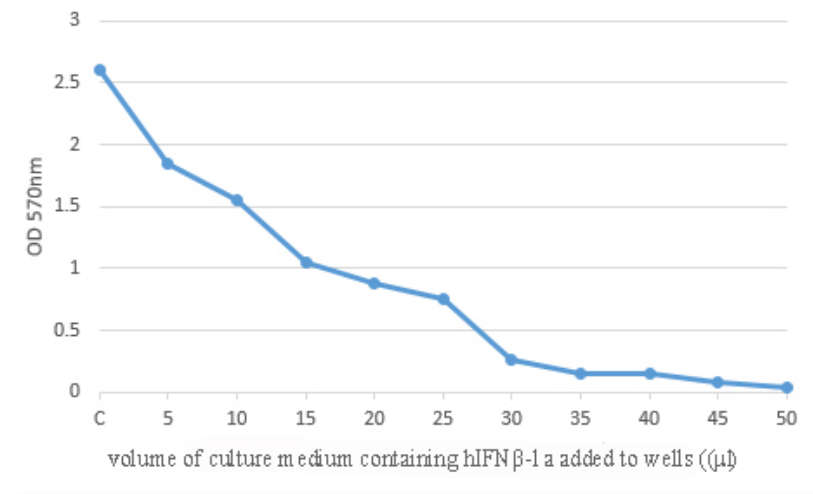

Figure 9. Linear diagram of $\mathrm{OD}$ at $570 \mathrm{~nm}$ by viable human dermal fibroblasts treated with different volumes $(0$ to $50 \mu \mathrm{L})$ of culture medium containing hIFN $\beta-1$ a protein produced by $\mathrm{CHO}$ cells. patterns in proteins, and thus the IFN $\beta$ protein produced by this system lacks a glycosylation pattern, and is different from its human variant. This reduces the efficacy of the drug compared to glycosylated form.

Various studies have shown that the production of recombinant human proteins in $\mathrm{CHO}$ cells is much higher than that of human cells. Another positive aspect of $\mathrm{CHO}$ cells is their immunity, which means that they are resistant to viral infections such as HIV, influenza, herpes, and measles, and unlike human cells, are generally regarded as safe cells (14). Post-translational modifications, glycosylation patterns, and disulfide bonds of proteins produced by this cell line are similar to those of humans, making $\mathrm{CHO}$ cells a very suitable cell line for the production of recombinant human proteins (15). Various strategies have been employed to increase the amount of recombinant protein production in $\mathrm{CHO}$ cells, such as regulating the culture temperature, adding chemicals, and bioreactor engineering (16). In one study, it was shown that after transfection of $\mathrm{CHO}$ cells, the temperature shift from $37^{\circ} \mathrm{C}$ to $32^{\circ} \mathrm{C}$ for 3 days increased interferon-gamma production by $40 \%$ compared to growth at $32^{\circ} \mathrm{C}$, and by $90 \%$ compared to growth at $37^{\circ} \mathrm{C}(17)$. Chemical compounds are also used to stop the cell cycle in the G phase, and thereby increase protein expression, including DMSO and sodium butyrate $(3,18)$. Using molecular chaperones is also an efficient way to increase protein expression in eukaryotic systems, especially $\mathrm{CHO}$ cells, by which the protein produced is protected against intracellular proteases. In a study, a protein disulfide isomerase (PDI) sequence was used as a molecular chaperone to protect and increase the levels of two recombinant interleukin-15 proteins and the TNF receptor produced by $\mathrm{CHO}$ cells, but PDI did not increase protein secretion (19). It is also important to optimize the production of interferon beta in $\mathrm{CHO}$ cells to increase the speed and quality and reduce the cost of drug production. For example, a change in codon preference in the destabilizing region of the end of the interferon beta protein was reported to increase the half-life of the corresponding mRNA, and consequently increase the production of this protein by 2.9 fold (20).

\section{Conclusion}

In this study, the $\mathrm{CHO}$ cells were used to produce recombinant hIFN $\beta$-1a protein because of the positive characteristics mentioned for this cell line. These cells were able to stably release the recombinant protein into the culture medium. We also used chemicals to increase efficiency, which satisfactorily increased the expression level. Further research should be done to increase protein expression, and particularly the cell stability should be investigated and employed to reduce the cost and time of drug production.

\section{Conflict of Interests}

The authors declare that they have no conflict of interests. 
Ethical Approval

Ethical considerations in this study included obtaining permission from the Ethics Committee of Malek Ashtar University of Technology (Ethical Code: GE96)

\section{Authors' Contribution}

Alireza Saeidinia, Mehdi Zeinoddini, and Rasoul Khalilzadeh conceived and designed the study; Nasrin Xodadadi performed the study and wrote the paper.

\section{Funding/Support}

This work received no funding or grant.

\section{Acknowledgments}

The authors acknowledge the support of the authorities of Malek-Ashtar University of Technology Biotech Research. This paper has been derived from the thesis project conducted in the Department of Bioscience and Biotechnology, Malek Ashtar University of Technology, Tehran, Iran in 2018, with the approval code of I2587413.

\section{References}

1. Amjadi O, Abedini M, Rafiei A, Safaii S, Ajami A, Hosseinian A. Interferons in autoimmune diseases: friend or foe. J Mazandaran Univ Med Sci. 2015;24(121):414-30. [Persian].

2. Day C, Schwartz B, Li BL, Pestka S. Engineered disulfide bond greatly increases specific activity of recombinant murine interferon-beta. J Interferon Res. 1992;12(2):13943. doi: 10.1089/jir.1992.12.139.

3. Allen MJ, Boyce JP, Trentalange MT, Treiber DL, Rasmussen B, Tillotson B, et al. Identification of novel small molecule enhancers of protein production by cultured mammalian cells. Biotechnol Bioeng. 2008;100(6):1193-204. doi: 10.1002/bit.21839.

4. van Beers MM, Sauerborn M, Gilli F, Brinks V, Schellekens $\mathrm{H}$, Jiskoot W. Oxidized and aggregated recombinant human interferon beta is immunogenic in human interferon beta transgenic mice. Pharm Res. 2011;28(10):2393-402. doi: 10.1007/s11095-011-0451-4.

5. Rommer PS, Zettl UK, Kieseier B, Hartung HP, Menge T, Frohman E, et al. Requirement for safety monitoring for approved multiple sclerosis therapies: an overview. Clin Exp Immunol. 2014;175(3):397-407. doi: 10.1111/cei.12206.

6. Skoko N, Argamante B, Grujicić NK, Tisminetzky SG, Glisin V, Ljubijankić G. Expression and characterization of human interferon-betal in the methylotrophic yeast Pichia pastoris. Biotechnol Appl Biochem. 2003;38(Pt 3):257-65. doi: 10.1042/ba20030065.

7. Rodriguez J, Spearman M, Huzel N, Butler M. Enhanced production of monomeric interferon-beta by $\mathrm{CHO}$ cells through the control of culture conditions. Biotechnol Prog. 2005;21(1):22-30. doi: 10.1021/bp049807b.

8. Caspeta L, Flores N, Pérez NO, Bolívar F, Ramírez OT. The effect of heating rate on Escherichia coli metabolism, physiological stress, transcriptional response, and production of temperature-induced recombinant protein: a scale-down study. Biotechnol Bioeng. 2009;102(2):468-82. doi: 10.1002/bit.22084.

9. Nekoufar S, Fazeli A, Fazeli MR. Solubilization of human interferon $\beta-1 \mathrm{~b}$ inclusion body proteins by organic solvents. Adv Pharm Bull. 2020;10(2):233-8. doi: 10.34172/ apb.2020.027.

10. Maldonado LM, Hernández VE, Rivero EM, Barba de la Rosa AP, Flores JL, Acevedo LG, et al. Optimization of culture conditions for a synthetic gene expression in Escherichia coli using response surface methodology: the case of human interferon beta. Biomol Eng. 2007;24(2):21722. doi: 10.1016/j.bioeng.2006.10.001.

11. Morowvat MH, Babaeipour V, Rajabi Memari H, Vahidi H. Optimization of fermentation conditions for recombinant human interferon beta production by Escherichia coli using the response surface methodology. Jundishapur J Microbiol. 2015;8(4):e16236. doi: 10.5812/jjm.8(4)2015.16236.

12. Fiore M, Degrassi F. Dimethyl sulfoxide restores contact inhibition-induced growth arrest and inhibits cell densitydependent apoptosis in hamster cells. Exp Cell Res. 1999;251(1):102-10. doi: 10.1006/excr.1999.4542.

13. Zuqueli R, Prieto C, Etcheverrigaray M, Kratje RB. Effect of sodium butyrate and zinc sulphate supplementation on recombinant human IFN- $\beta$ production by mammalian cell culture. Lat Am Appl Res. 2006;36(4):321-27.

14. Kay M, Hojati Z, Heidari M. Design and production of recombinant interferon beta construct with specific mutations in Kozak sequence due to promote translation. Razi J Med Sci. 2015;22(138):68-77. [Persian].

15. Kim JM, Kim JS, Park DH, Kang HS, Yoon J, Baek K, et al. Improved recombinant gene expression in $\mathrm{CHO}$ cells using matrix attachment regions. J Biotechnol. 2004;107(2):95105. doi: 10.1016/j.jbiotec.2003.09.015.

16. Liu $\mathrm{CH}$, Chen LH. Enhanced recombinant M-CSF production in $\mathrm{CHO}$ cells by glycerol addition: model and validation. Cytotechnology. 2007;54(2):89-96. doi: 10.1007/ s10616-007-9078-z.

17. Fox SR, Patel UA, Yap MG, Wang DI. Maximizing interferon-gamma production by Chinese hamster ovary cells through temperature shift optimization: experimental and modeling. Biotechnol Bioeng. 2004;85(2):177-84. doi: 10.1002/bit.10861.

18. Jiang Z, Sharfstein ST. Sodium butyrate stimulates monoclonal antibody over-expression in $\mathrm{CHO}$ cells by improving gene accessibility. Biotechnol Bioeng. 2008;100(1):189-94. doi: 10.1002/bit.21726.

19. Davis R, Schooley K, Rasmussen B, Thomas J, Reddy P. Effect of PDI overexpression on recombinant protein secretion in CHO cells. Biotechnol Prog. 2000;16(5):73643. doi: 10.1021/bp000107q.

20. Bezi Z, Korbekandi H, Hashemibeni B, Hojati Z, Moradi Hassanabad A, Marasi MR. Improvement of interferonbeta production in transient expression system of CHO DG 44 by a codon bias change in instability sequence (CRID) of C-terminal of interferon beta gene. J Isfahan Med Sch. 2012;30(182):1-10. 